\title{
miR-21-3p inhibits autophagy of bovine granulosa cells by targeting VEGFA via PI3K/AKT signaling
}

\author{
Lizhu Ma1,*, Yuxin Zheng1,*, Xiaorong Tang ${ }^{1}$, Huimin Gao ${ }^{1}$, Ning Liu, Yan Gao², \\ Lizhuang $\mathrm{HaO}^{3}$, Shujie $\mathrm{Liu}^{3}$ and Zhongliang Jiang ${ }^{1}$ \\ ${ }^{1}$ College of Animal Science and Technology, Key Laboratory of Animal Genetic, Breeding and Reproduction in \\ Shaanxi Province, Northwest A \& F University, Yangling, China, ${ }^{2}$ Faculty of Medical and Chemical Engineering, \\ Xianyang Vocational Technical College, Xi'an, China and ${ }^{3}$ State Key Laboratory of Plateau Ecology and Agriculture, \\ Key Laboratory of Plateau Grazing Animal Nutrition and Feed Science of Qinghai Province, Qinghai Plateau Yak \\ Research Center, Qinhai University, Xining, China
}

Correspondence should be addressed to Z Jiang; Email: jiangzhongliang@nwafu.edu.cn

*(L Ma and $\mathrm{Y}$ Zheng contributed equally to this work)

\begin{abstract}
It is well documented that granulosa cell apoptosis is the main reason for follicular atresia and death; however, increasing evidence suggests that autophagy plays an important role in the fate of granulosa cells. miR-21-3p regulates many fundamental biological processes and is pivotal in the autophagy of tumor cells; nevertheless, the autophagy in cattle ovary and how miR-21-3p regulates the follicular cells is unknown. In this study, we aimed to elucidate the autophagy and the role of miR-21-3p in cattle ovary using bovine primary ovarian granulosa cells (BGCs). The results showed the autophagy for the first time in BGCs in large follicle according to autophagic gene transcript of $L C 3, B E C N-1, A T G 3$, protein expression of LC3, P62 and LC3 puncta, a standard marker for autophagosomes. miR-21-3p was identified as a novel miRNA that repressed BGCs autophagy according to the results from plasmids transfection of miR-21-3p mimics and inhibitor. Meanwhile, VEGFA was confirmed to be a validated target of miR-21-3p in BGCs using luciferase reporter assays and the results of VEGFA expression decreased with transfection of miR-21-3p mimics, while it increased with transfection of miR-21-3p inhibitor. In addition, small interference-mediated knockdown of VEGFA significantly inhibits BGCs autophagy signaling; however, overexpression of VEGFA in BGCs promoted autophagy in the presence of miR-21-3p. Finally, the results of AKT and its phosphorylation suggested that miR-21-3p suppressed VEGFA expression through downregulating AKT phosphorylation signaling. In summary, this study demonstrates that miR-21-3p inhibits BGCs autophagy by targeting VEGFA and attenuating PI3K/AKT signaling.

Reproduction (2019) 158 441-452
\end{abstract}

\section{Introduction}

In mammalian ovaries, more than $99 \%$ of the ovarian follicles are destroyed due to follicular atresia (Faddy et al. 1992, Shen et al. 2017). Previous studies revealed that follicular atresia occurs due to granulosa cells (GCs) apoptosis (Krysko et al. 2008). However, recent studies suggest that autophagy can be induced in human GCs during follicular atresia which promotes apoptotic cell death (Choi et al. 2011, Hulas-Stasiak \& Gawron 2011). Autophagy is an evolutionarily conserved intracellular process which engulfs long-lived proteins and damaged organelles for degradation and recycling (Yu et al. 2018). Several markers of autophagy are well characterized, such as microtubule-associated protein light chain 3 (LC3), beclin-1 (BECN1) and autophagyrelated proteins including ATG3 and ATG7 (Gawriluk \& Rucker 2015). Upon initiation of autophagy, ATG4 cleaves pro-LC3 to form LC3-I, which is then conjugated to phosphatidylethanolamine (PE) by ATG7 (Zhou et al. 2016, 2019) for the formation of the autophagosomes. Beclin-1 is also essential for the formation of the autophagosome.

Autophagy of the oocyte plays a key role in the loss of germ cells after birth and in follicular atresia during puberty, with autophagosomes clearly detectable in the oocyte (Hulas-Stasiak \& Gawron 2011), whereas autophagy-mediated GCs apoptosis is only involved in antral follicle atresia (Choi et al. 2010). FSH-FOXO1 signaling has been suggested to protect against oxidative damage to GCs by restraining autophagy in granulosa cells (Shen et al. 2017). Numerous studies suggest that autophagy directly regulates follicular atresia and mediates apoptotic GCs death during folliculogenesis (Hulas-Stasiak \& Gawron 2011).

miRNAs are 22 24 nucleotide non-coding RNAs that are evolutionarily conserved and function as negative 
regulators of gene expression (Megraw et al. 2007). MiRNAs downregulate gene expression by either inducing the degradation of target mRNAs or affecting translation by binding to 3' untranslated regions (UTRs) of mRNAs (Chai et al. 2013). MiRNAs control various fundamental biological processes including cell development, proliferation, differentiation and apoptosis, and play a central role in the regulation of autophagy (Xu \& Mo 2012, Xu et al. 2016). One such miRNA, miR-21-3p, is known to serve vital functions in the development and apoptosis in ovarian cancer cells (Perla et al. 2016) and is upregulated in solid and hematological cancer tissue, where it downregulates tumor suppressors including PTEN phosphatase and actin-binding protein tropomyosin I (Volinia et al. 2006, Petrocca et al. 2008, Zhang et al. 2008). However, whether miR-21-3p is expressed in bovine ovaries and its role in bovine ovarian granulosa cell (BGCs) remains undefined.

Vascular endothelial growth factor A (VEGFA) composed of ligand and receptor plays a pivotal role in tissue vascularization and endothelial cell growth (Shibuya 2011). Inbovineovary, VEGFA mRNAabundance was greater in GCs than theca cells (TC) and decreased in TC during follicle development (Nichols et al. 2019). VEGFA expression activates PI3K/Akt signaling and regulates the mammalian target of rapamycin (mTOR) signaling (Edinger \& Thompson 2002). Studies suggested that Akt signal to mTOR through its ability to decrease the AMP/ATP ratio, thus preventing AMPK inhibition of TSC1/2 (Hahn-Windgassen et al. 2005). Although AKT is a key regulator of autophagy (Choi et al. 2014), the relationship between AKT activation and VEGFA expression in BGC remains undefined.

In the present study, we hypothesized that autophagy in BGCs is regulated by miR-21-3p. To test this hypothesis, we determined the effects of miR-21-3p mimic or inhibitor on bovine GCs autophagy in vitro and assessed the role that VEGFA plays.

\section{Materials and methods Cell culture}

The experiment was approved by the Institutional Animal Care and Use Committee of the Northwest A\&F University under permit number 2016ZX08008002.

Bovine ovaries were collected at a local slaughterhouse from adult Qinchuan cattle aged 4-6 years, irrespective of the stage of estrous cycle. The ovaries were transferred to the laboratory in saline with antibiotics $(100 \mathrm{U} / \mathrm{mL}$ of penicillin and $100 \mu \mathrm{g} / \mathrm{mL}$ of streptomycin) within $2 \mathrm{~h}$. The ovarian follicles were divided into three groups of $<2 \mathrm{~mm}$ (Small); $2 \sim 6 \mathrm{~mm}$ (Medium) and $>6 \mathrm{~mm}$ (Large) diameter, and a $5 \mathrm{~mL}$ syringe with 23-gauge needle was used to aspirate GCs with follicular fluid from follicles. For each experimental replicate, at least 20 ovaries were collected to obtain enough GCs from small, medium and large follicles. Cell suspensions were filtered through a
150 mesh steel sieve (Sigma-Aldrich) and centrifuged at $1500 \mathrm{rpm}$ for $5 \mathrm{~min}$. The number of cells was counted using Trypan blue dye exclusion procedure and the follicular fluid was used to measure the concentration of estradiol and progesterone.

GCs were cultured in serum-free conditions and estradiol secretion and responsiveness to FSH were determined using the procedures described by Jiang et al. (2013) with a few modifications. Briefly, GCs were seeded into 12-well tissue culture plates (Corning Inc., Nanjing, China) at a density of $5 \times 10^{6}$ viable cells in $2 \mathrm{~mL}$ of DMEM/F12 containing sodium bicarbonate $(10 \mathrm{mM})$, sodium selenite $(4 \mathrm{ng} / \mathrm{mL})$, bovine serum albumin (BSA) $(0.1 \%$, W/V, Sigma-Aldrich), penicillin $(100 \mathrm{U} / \mathrm{mL})$, streptomycin $(100 \mu \mathrm{g} / \mathrm{mL})$, transferrin $(2.5 \mu \mathrm{g} / \mathrm{mL})$, nonessential amino acids $(1 \mathrm{mmol} / \mathrm{L})$, bovine insulin $(10 \mathrm{ng} / \mathrm{mL})$, androstenedione $\left(10^{-7} \mathrm{M}\right)$ and bovine $\mathrm{FSH}(1 \mathrm{ng} / \mathrm{mL}$, BIONICHE Inc., Ontario, Canada). Cultures were maintained at $37^{\circ} \mathrm{C}$ in $5 \% \mathrm{CO}_{2}$ and $95 \%$ air for 6 days, with $70 \%$ fresh medium change every 2 days, Experimental treatments were applied on day 3 (the day of GCs collection is day 0 ).

\section{Plasmid construction}

The 3' UTR of VEGFA containing predicted miR-21-3p-binding sites was synthesized by Ribobio Company (Guangzhou, China). Bovine miR-21-3p mimic, inhibitor, specific siRNA (si-Vegfa) were synthesized and purchased from Ribobio Company (Guangzhou, China) and VEGFA overexpression constructs (oe-Vegfa) was synthesized and purchased from Tsingke Company (Nanjing, China). Sequences were cloned into pmiR-RB Dual-Luciferase miRNA Target Expression Vectors (Promega). Plasmids encoding GFP-LC3 were kindly provided by Prof. Baojun Zhang of Xian Jiaotong University, Shaanxi, China.

\section{Cell transfection}

BGCs were transfected using Lipofectamine 3000 (Life Technologies) according to the manufacturer's instructions. Negative control (50 nM), mimic (50 nM), inhibitor (100 nM), and VEGFA siRNA (si-Vegfa, $50 \mathrm{nM}$ ) and overexpression (oe-Vegfa, $1 \mu \mathrm{g} / \mathrm{mL}$ ) plasmids were applied to the cells for $6 \mathrm{~h}$ at $37^{\circ} \mathrm{C}$ in $5 \% \mathrm{CO}_{2}$ and $95 \%$ air, after which the cell culture medium was replaced with fresh medium and the cells were cultured for $42 \mathrm{~h}$ before the cells were harvested for RNA or protein extraction.

\section{Dual-luciferase reporter analysis}

The $3^{\prime}$-UTR of VEGFA containing the predicted miR-21-3pbinding site and point mutations at this site were synthesized by Ribobio Company (Guangzhou, China). Sequences were cloned into pmiR-RB Dual-Luciferase miRNA Target Expression Vectors (Promega). BGCs were co-transfected with pmiR-RB-Vegfa-WT or pmiR-RB-Vegfa-MUT reporter (50 nM, respectively) plasmids together with miR-21-3p mimic, inhibitor or negative controls using Lipofectamine 3000 (Life Technologies). Firefly and Renilla luciferase activity were determined by dual-luciferase reporter assays. 


\section{Monodansylcadaverine (MDC) and DAPI labeling}

MDC is a lysosomotropic compound useful for the identification of autophagic vesicles and the MDC-labeled vesicle appears bright and punctate under fluorescence microscopy. In this experiment, BGCs were grown in 24-well plates and co-transfected with miR-21-3p mimics and GFP-LC3 on day 3 for $6 \mathrm{~h}$. The post-transfection cells were incubated with $0.05 \mathrm{mM}$ MDC and/or $4^{\prime} 6^{\prime}$-diamidino-2-phenylindole (DAPI, $1 \mu \mathrm{g} / \mathrm{mL}$ ) at $37^{\circ} \mathrm{C}$ for $15 \mathrm{~min}$, immediately followed by fixation in paraformaldehyde (4\%) in PBS for $20 \mathrm{~min}$. Cells were analyzed immediately under a fluorescence microscope (excitation: $390 \mathrm{~nm}$, emission: $460 \mathrm{~nm}$ ). A total of 200 cells in each sample were analyzed and the percentage with punctate staining was calculated.

\section{RNA extraction and quantitative real-time PCR}

After transfection, the culture medium was removed and total RNA was extracted from BGCs using TRIzol reagent (Invitrogen Company) according to the manufacturer's instructions. Total RNA was quantified by absorbance at $260 \mathrm{~nm}$. MiRNA cDNA was synthesized from the purified total RNA (500 ng) using the qScript microRNA Synthesis Kit (Quanta Biosciences, Inc., Beverly, MA, USA).Quantitative real-time PCR for gene expression was performed with SYBR Green I PCR Master Mix in a reaction volume of $20 \mu \mathrm{L}$ using the $A B I$ system (Applied Biosystems 7900) and for miR-21-3p with PerfeCTa SYBR Green SuperMix, Low ROX (Quanta Biosciences). Common thermal cycling parameters $\left(3 \mathrm{~min}\right.$ at $95^{\circ} \mathrm{C}, 40$ cycles of $15 \mathrm{~s}$ at $95^{\circ} \mathrm{C}, 30 \mathrm{~s}$ at $59^{\circ} \mathrm{C}$, and $30 \mathrm{~s}$ at $72^{\circ} \mathrm{C}$ ) were used to amplify each transcript. Melting-curve analyses were performed to verify product identity. GAPDH was used as ahousekeeping gene for normalization of the expression levlel of mRNA, and $U 6$ gene was used to normalize the expression level of miR-21-3p. The miR-21-3p and mRNA (VEGFA, BECN1, LC3, ATG3 and GAPDH) expression was calculated using $\Delta \mathrm{Ct}=\left(\mathrm{Ct}_{\text {miR-21-3p }}-\mathrm{Ct}_{\mathrm{U} 6}\right)$ and $\Delta \mathrm{Ct}=\left(\mathrm{Ct}_{\mathrm{mRNA}}-\mathrm{Ct}_{\mathrm{GAPDH}}\right)$ respectively. The relative expression of miR-21-3p was calculated using the $2^{-\Delta \Delta \mathrm{Ct}}$ method. All samples were assessed in triplicate. Bovine specific primers for the target genes are listed in Table 1.

\section{Western blotting}

GCs were washed with cold PBS and lysed in RIPA buffer containing protease inhibitors. The protein content of the samples was determined by BCA assays (Pierce Inc., USA).
Total proteins $(15 \mu \mathrm{g})$ were separated on $15 \%$ SDS-PAGE gels and transferred to a polyvinylidene difluoride membranes (PVDF, Millipore) in a Bio-Rad wet Blot Transfer Cell apparatus (transfer buffer: $39 \mathrm{mM}$ glycine, $48 \mathrm{mM}$ Tris-base, 1\% SDS, $20 \%$ methanol, $\mathrm{pH}$ 8.3). Membranes were blocked in TBST $(150 \mathrm{mM} \mathrm{NaCl}, 2 \mathrm{mM} \mathrm{KCl}, 25 \mathrm{mM}$ Tris, $0.05 \%$ Tween20, $\mathrm{pH}$ 7.4) containing $5 \%$ BSA for $2 \mathrm{~h}$ at room temperature. Membranes were probed with primary antibody: LC3 (Rabbit polyclonal to LC3I/II, 1:2000, \# L8918, Abcam), VEGFA (Rabbit polyclonal to VEGFA, 1:2000, \# ab39250, Abcam), P62 (Rabbit polyclonal to P62 1:2000, \# ab101266, Abcam), AKT (Rabbit polyclonal to AKT, 1:3000, \# ab64148, Abcam), phospho-AKT (Rabbit polyclonal to phosphor-AKT, 1:3000, $\#$ ab8932, Abcam) and $\beta$-actin (Rabbit polyclonal to $\beta$-actin, 1:5000; \#4970, Cell Signaling Technology) in QuickBlock ${ }^{\mathrm{TM}}$ Primary Antibody Dilution Buffer (Beyotime biotechology, Tianjin, China) at $4{ }^{\circ} \mathrm{C}$. Membranes were then washed and labeled for $2 \mathrm{~h}$ at room temperature with anti-rabbit HRPconjugated IgG (1:4000, LK2003, Sungene Biotechnology, Tianjin, China) diluted in QuickBlock ${ }^{\mathrm{TM}}$ Secondary Antibody Dilution Buffer (Beyotime Biotechology, China). Membranes were washed in TBST, and protein bands were visualized via chemiluminescence (ECL, Millipore). Semi-quantitative analysis was performed with NIH Image J software.

\section{Statistical analysis}

All experiments were performed in triplicate. Independent $t$-test was used to evaluate the significance of the results between groups. ANOVA was used to test the main effects among treatments, and culture replicate was included as a random variable in the $F$-test. Differences between means were tested with the Tukey-Kramer HSD test. Statistical analyses were performed using GraphPad Prism 6 software (GraphPad software Inc.). Data were presented as the means \pm S.E.M.

\section{Results}

\section{Autophagy of BGCs in ovarian follicles}

We first investigated the expression of autophagy-related genes and miR-21-3p in BGCs isolated from small (diameter $<2 \mathrm{~mm}$ ), medium (diameter of 2 6 $\mathrm{mm}$ ) or large size follicles (diameter $>6 \mathrm{~mm}$ ). Quantitative real-time PCR was used to detect relative gene expression. The results indicated that markers of autophagy (LC3, BECN-1 and ATG3) and VEGFA were

Table 1 Specific primer sequences used for real-time PCR.

\begin{tabular}{|c|c|c|}
\hline Genes & Forward & Reverse \\
\hline GADPH & 5'-CACССТCAAGATTGTCAGCA-3' & 5'-GGTCATAAGTCCCTCCACGA-3' \\
\hline VEGFA & 5'-GGCTGCTGTAATGACGAAAG-3' & 5'-САTСТСТССТАTGTGCTGGCT-3' \\
\hline LC3 & 5'-TTATCCGAGAGCAGCAGCATCC-3' & 5'-AGGCTTGATTAGCATTGAGC-3' \\
\hline$B E C N-1$ & 5'-AGTTGAGAAAGGCGAGACAC-3' & 5'-GATGGAATAGGAACCACCAC-3' \\
\hline ATG3 & 5'-GGTTGTTCGGCTATGATGAG-3' & 5'-GGGAGATGAGGGTGATTTTC-3' \\
\hline$B C L-2$ & 5'-ATGACTTCTCTCGGCGCTAC-3' & 5'-CTGAAGAGCTCCTCCACCAC-3' \\
\hline$B A X$ & 5'-AACATGGAGCTGCAGAGGAT-3' & 5'-CAGTTGAAGTTGCCGTCAGA-3' \\
\hline U6 & 5'-GCTTCGGCAGCACATATACT-3' & 5'-TTCACGAATTTGCGTGTCAT-3' \\
\hline$m i R-21-3 p$ & 5'-CAACAGCAGTCGATGGGCTGT-3' & \\
\hline
\end{tabular}


higher, but miR-21-3p expression was lower in large follicles compared to small or medium follicles (Fig. 1A). Western blot demonstrated that LC3 protein levels were higer in BGCs from large follicles compared with cells from small and medium follicles (Fig. 1B). GFP-LC3 was transfected into BGCs and a significant accumulation of GFP-LC3 puncta was observed in large follicles (Fig. 1C). To further assess the growth status of GCs in vitro, we measured the relative expression of $B C L-2$ (anti-apoptotic), $B A X$ (proapoptotic) and the ratio of $B C L$ $2 / B A X$. The ratio of $B C L-2 / B A X$, rather than the absolute concentration of either, is predictive of cell survival, and their relative expression has been reported to be a better predictor of outcome for cell fate (de la Torre et al. 2007). The ratio of $B C L-2 / B A X$ was higher in medium-sized follicles compared to small and large follicles (Fig. 1D). These results demonstrated that autophagy and apoptosis primarily occur in the BGCs of large follicles. GCs isolated from small or medium size follicles were therefore selected for subsequent experiments.

\section{miR-21-3p inhibits autophagy in BGCs}

We next investigated whether miR-21-3p alters autophagy in BGCs. miR-21-3p mimics or inhibitor were transfected into BGCs, and MDC was used to label autophagic vacuoles after transfection (Fig. 2A). As shown in Fig. 2B, the miR-21-3p mimic significantly increased miR-21-3p expression levels up to 478-fold and transfection of miR-21-3p mimic decreased the abundance of LC3, BECN-1 and ATG3 mRNA. Transfection of the miR-21-3p inhibitor decreased miR-21-3p levels but increased $L C 3, B E C N-1$ and ATG 3 mRNA levels (Fig. 2C). Western blotting was performed to assess LC3 and P62 levels following transfection with miR-21-3p mimic or inhibitor. Similar to the gene expression analysis, Western blot results revealed that the abundance of LC3 decreased after transfection with miR-21-3p mimic and increased after treatment with miR-21-3p inhibitor (Fig. 2D). The miR-21-3p inhibitor significantly decreased P62 protein levels but the miR-21-3p had no effect (Fig. 2D). Together, these results indicate that miR-21-3p represses autophagy in BGCs.

\section{miR-21-3p targets VEGFA}

To investigate the mechanism(s) by which miR-21-3p inhibits autophagy in BGCs, TargetScan (www.targetscan.org) was used as a gene prediction program to identify autophagy-related genes that contain miR-21-3p response elements in the $3^{\prime} U T R$. The results showed that VEGFA is a candidate miR-21-3p target. To confirm these results, we introduced destabilizing mutations to key interaction residues in the putative miRNAbinding sites, including a residue in the seed-match sequence (Fig. 3A). Luciferase assays showed that exogenous miR-21-3p led to a reduction in luciferase activity in 293T cells transfected with 3'-UTR VEGFA constructs, but had no effects on luciferase activity for the putative miR-21-3p-binding sites in the mutant VEGFA 3'-UTR (Fig. 3B). VEGFA expression at the mRNA and protein levels was determined in BGCs following transfection with miR-21-3p mimic or inhibitor plasmids, respectively. The results indicated that the VEGFA mRNA levels decreased in cells transfected with miR-21-3p mimic, while the miR-21-3p inhibitor increased VEGFA gene expression (Fig. 3C). VEGFA protein levels were altered in a similar manner (Fig. 3D). These results demonstrate that VEGFA is a validated target of miR-21-3p in BGCs.

\section{VEGFA silencing inhibits BGCs autophagy}

To understand the role of VEGFA in GCs autophagy, we used a siRNA approach to successfully reduce VEGFA mRNA and protein levels (Fig. 4A and B). Reducing VEGFA levels significantly decreased $L C 3, B E C N-1$ and ATG 3 mRNA (Fig. 4A) and LC3 protein levels, and increased $\mathrm{P} 62$ protein abundance (Fig. 4B). To assess if VEGFA mediates the effects of miR-21-3p on autophagy, rescue experiments were performed. Addition of the miR-21-3p inhibitor increased VEGFA protein levels as expected from the previous experiment, and cotreatment with si-VEGFA abrogated this effect (Fig. 4C). Similarly, miR-21-3p inhibitor increased LC3 protein levels, which was abolished by cotreatment with si-VEGFA. Inversely, miR-21-3p inhibitor decreased P62 protein levels, and cotreatment with si-VEGFA increased P62 levels above those seen in controls (Fig. 4C). These results indicate that VEGFA silencing inhibits BGCs autophagy in the presence of miR-21-3p.

\section{Overexpression of VEGFA promotes autophagy in BGCs}

To confirm that miR-21-3p acts through VEGFA to induce autophagy, VEGFA was overexpressed in the presence or absence of miR-21-3p mimics. Transfection with a VEGFA expression plasmid increased VEGFA mRNA and protein levels (Fig. 5A and B), significantly increased $L C 3, B E C N-1$ and ATG3 mRNA levels (Fig. 5A), and increased LC3 (I and II) but decreased P62 protein levels (Fig. 5B), suggesting that autophagy was activated in BGCs in response to elevated VEGFA levels. Transfection of the miR-21-3p mimics significantly decreased the levels of LC3 and VEGFA protein compared to control, while no differences were observed in cells co-transfected with oe-Vegfa and miR-21-3p mimics (Fig. 5C). In contrast, P62 levels were significantly reduced in BGCs treated with the miR-21-3p mimics with or without co-transfecteion with oe-Vegfa (Fig. 5C). Together, these results indicate that VEGFA overexpression promotes autophagy in BGCs.

\section{miR-21-3p prevents AKT phosphorylation in BGCs}

AKT is a known regulator of autophagy (Choi et al. 2014). To determine whether miR-21-3p activates AKT by suppressing VEGFA expression, Western blot analysis was performed to measure AKT phosphorylation ( $p-A K T$ ) following the treatment with miR-21-3p mimics, inhibitors, and after VEGFA knowndown and overexpression. The results indicated that the levels of $\mathrm{p}$-AKT decreased following transfection of the miR21-3p mimics, while the miR-21-3p inhibitor increased $p$-AKT levels (Fig. 6A). Consistent with these findings, p-AKT levels were significantly lower in BGCs treated with si-Vegfa (Fig. 6B) and were significantly higher in BGCs overexpressing VEGFA (Fig. 6C) compared to negative controls. These findings suggest 

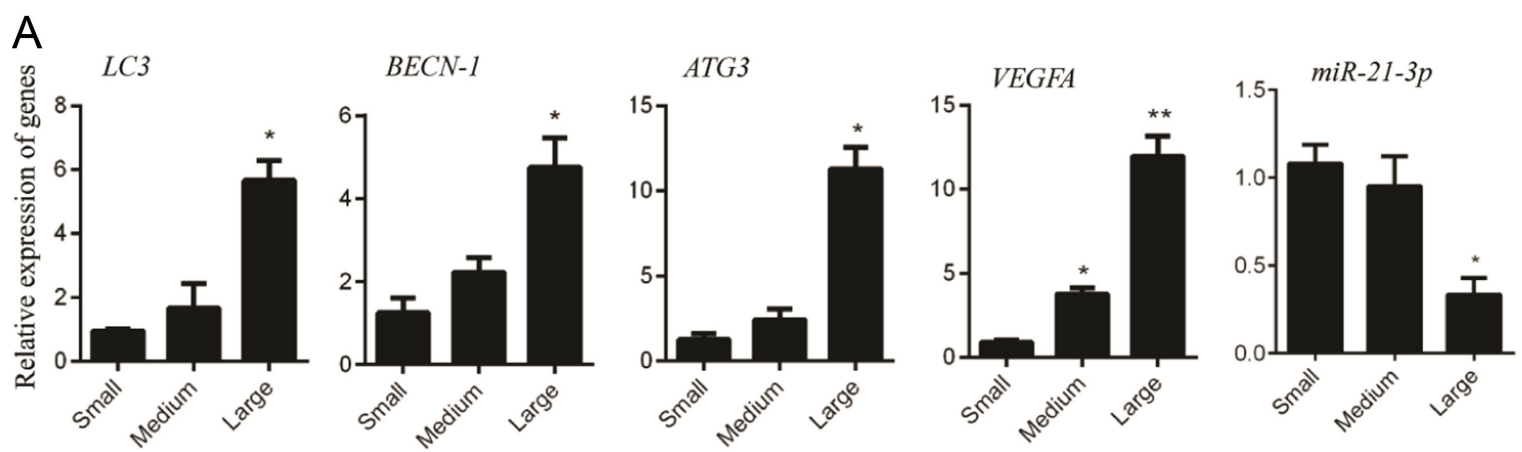

B
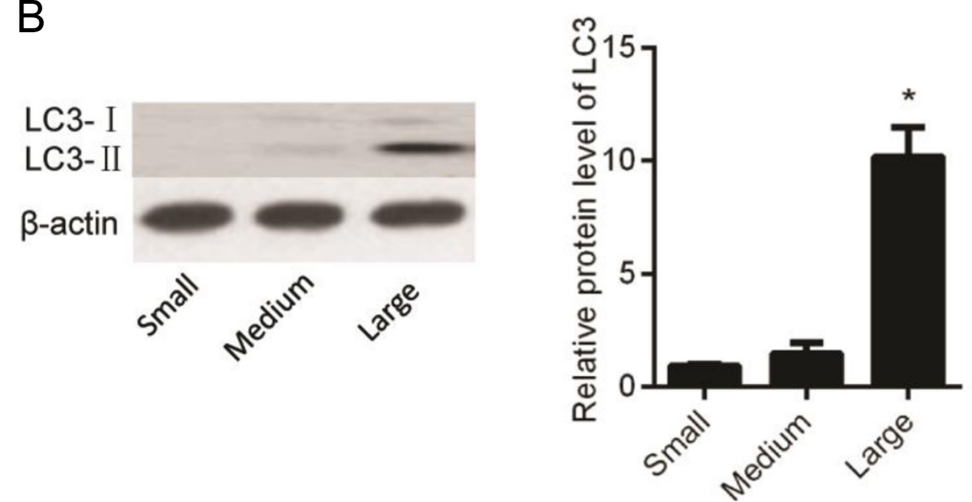

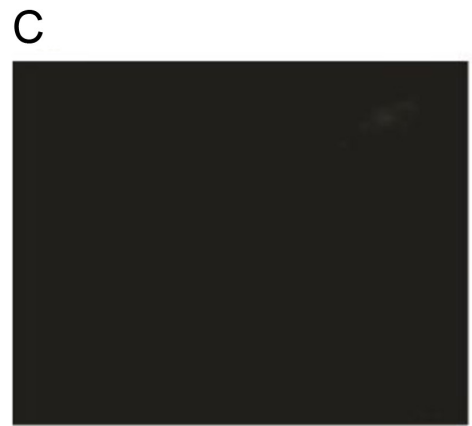

Small

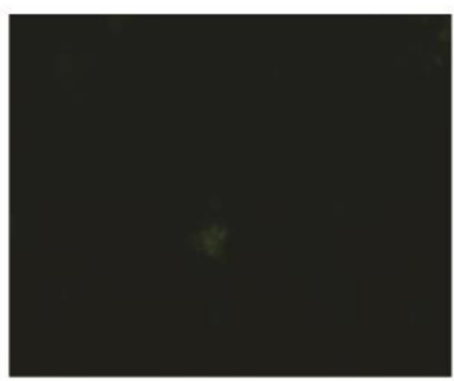

Medium

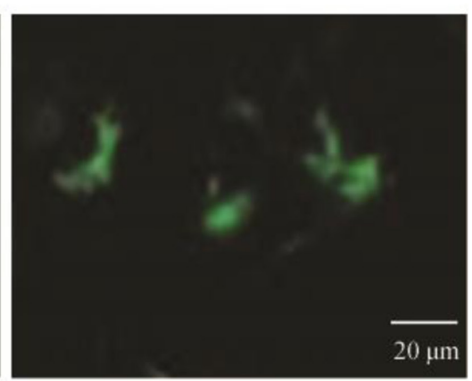

Large

D
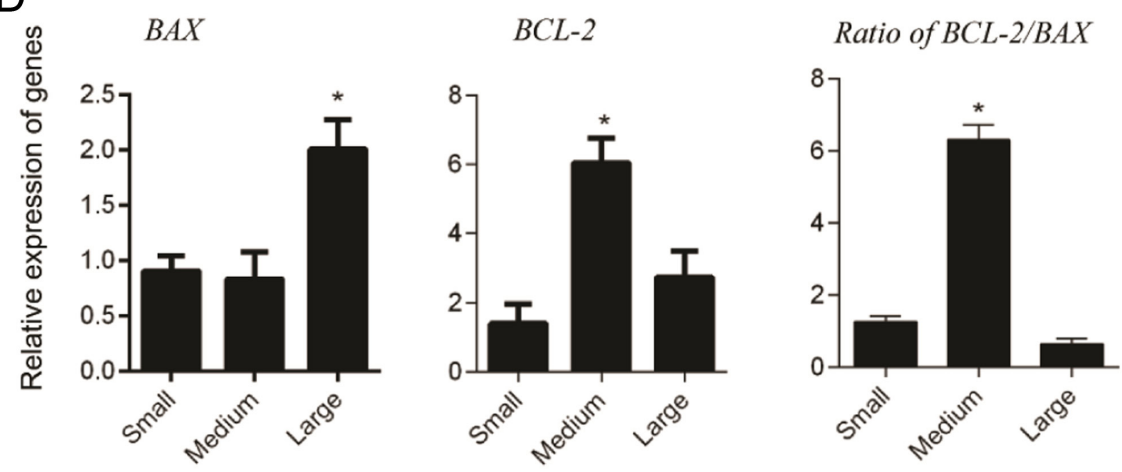

Figure 1 Expression of autophagic marker genes and miR-21-3p in BGCs. (A) Cells were aspirated from follicles using a syringe, and real-time PCR analysis of autophagic marker genes and miR-21-3p expression in BGCs from small, medium and large follicles. (B) Western blot analysis of LC3 levels in the BGCs of follicles. (C) GFP-LC3 puncta accumulate in the follicles. BGCs were transfected with GFP-LC3 plasmids, and autophagy was assessed after $24 \mathrm{~h}$. (D) BCL-2 and BAX mRNA levels and the ratio of $B C L-2 / B A X$ in BGCs were determined. Bar $=20 \mu \mathrm{m}$. Data are means \pm S.E.M. of three independent experiments, bars with no common asterisk are significantly different $(P<0.05)$. Note: small: small follicle; medium: medium follicle; large: large follicle. 

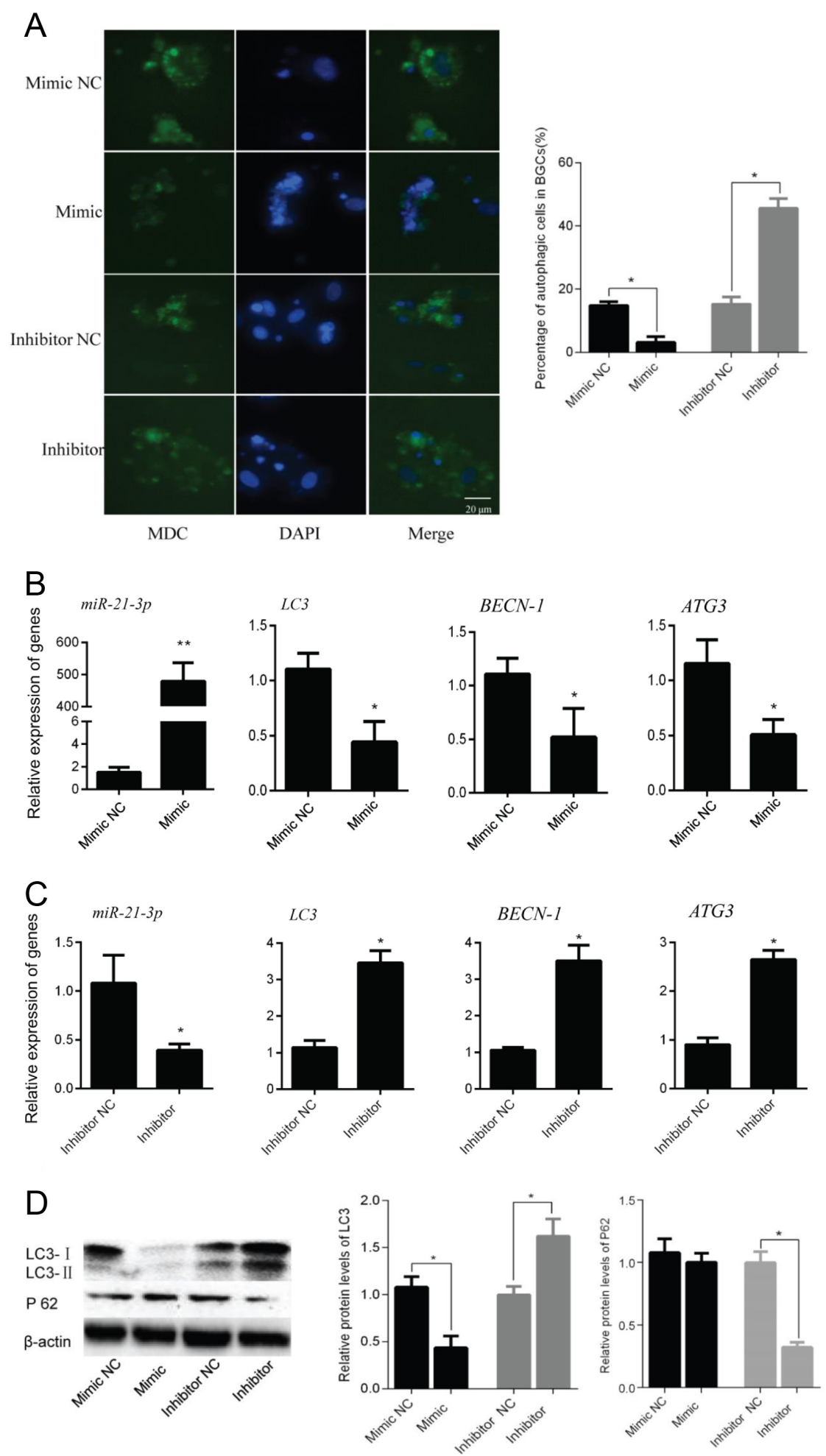

Figure 2 miR-21-3p inhibits BGC autophagy. (A) Cells were transfected with miR-21-3p mimic or inhibitor, and after 24h, autophagy was assessed by MDC staining. Bars $=20 \mu \mathrm{m}$. Percentage of MDC-positive cells (the puncta) were calculated and represented in the graph. (B) Real-time PCR analysis of $L C 3, B E C N-1, A T C 3$ and miR-21-3p after transfection with miR-21-3p mimic to cells for $6 \mathrm{~h}$ and cultured for $42 \mathrm{~h}$ with fresh medium. (C) Real-time PCR analysis of $L C 3, B E C N-1, A T G 3$ and miR-21-3p after transfection with miR-21-3p inhibitor to cells for $6 \mathrm{~h}$ and cultured for $42 \mathrm{~h}$ with fresh medium. (D) Western blot analysis of LC3 and P62 after transfection miR-21-3p mimic or inhibitor to cells for $6 \mathrm{~h}$ and cultured for $42 \mathrm{~h}$ with fresh medium. Band intensities were calculated using Image J software. Data are means \pm S.E.M. of three independent replicate, bars with no common asterisk are significantly different $(P<0.05)$. 

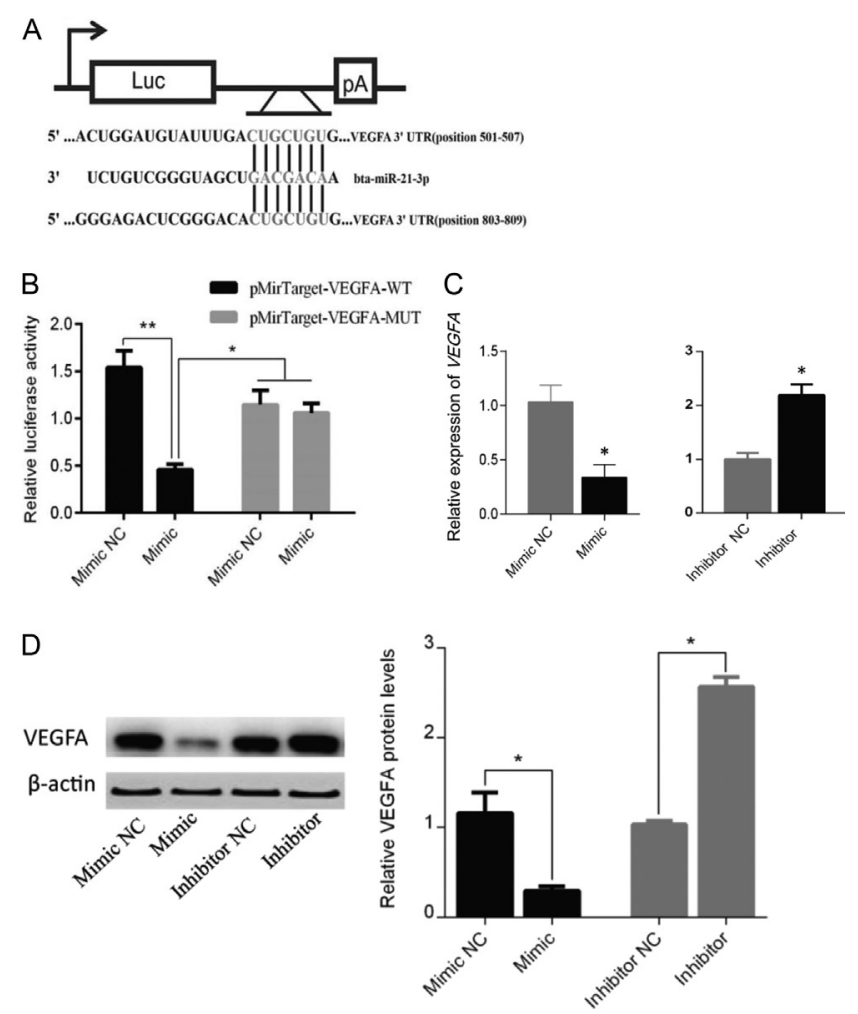

Figure 3 miR-21-3p targets VEGFA. (A) Binding sites of miR-21-3p and VEGFA. (B) Luciferase reporter assays showing that VEGFA is a direct target of miR-21-3p. (C) Real-time PCR analysis showing effects of miR-21-3p mimic and inhibitor on VEGFA mRNA levels in BGCs after treatment for $6 \mathrm{~h}$ and cultured for $42 \mathrm{~h}$ with fresh medium. (D) Western bolt analysis showing effects of miR-21-3p on VEGFA expression after plasmids transfection for $6 \mathrm{~h}$, and cultured for $42 \mathrm{~h}$ with fresh medium. Data are means \pm S.E.M. of three independent replicates, bars with no common asterisk are significantly different $(P<0.05)$.

that miR-21-3p inhibits BGCs autophagy by targeting VEGFA and downregulating AKT phosphorylation (Fig. 6D).

\section{Discussion}

The earliest stage of atresia in antral follicles is GC apoptosis (Yu et al. 2004, Choi et al. 2010, Matsuda et al. 2012), and increasing evidence suggests that autophagy plays an important role in the survival and proliferation of GCs (D'Herde et al. 1996, Choi et al. 2010, Shen et al. 2017, Zhou et al. 2017). In rat GCs, the accumulation of autophagosomes induced by serum starvation activates apoptosis by reducing $\mathrm{Bcl}-2$ expression, leading to caspase activation (Choi et al. 2011). Interestingly, specific silencing of autophagy-related genes results in a significant reduction in the primordial follicular pool suggesting that a major role of autophagy is to regulate follicular development and maintain ovarian primordial follicular reserves (Gawriluk et al. 2011, Song et al. 2015). Although studies have elucidated the role of GC autophagy in follicular atresia in rodents, evidence of the role for autophagy in BGC is absent. In the present study, LC3, BECN-1 and ATG3 mRNA levels were measured because the cytosolic form of LC3 (LC3-I) is recruited to autophagosomal membranes (Zhou et al. 2016, Cao et al. 2017), BECN1 is an essential for autophagosome formation, and the activity of ATG3 is involved in the formation of LC3-II on the surface of autophagosomes by binding to ATG7 (Zhou et al. 2019). Here, we provide direct evidence that autophagy occurs in BGCs and we reveal the role of miR-21-3p in controlling the level of autophagy in BGCs. We demonstrate that (1) miR21-3p regulates BGCS autophagy; (2) VEGFA is a target of miR-21-3p in BGCs; and (3) miR-21-3p inhibits BGC autophagy by downregulating AKT phosphorylation. Collectively, these results demonstrate that miR-21-3p plays an important role in BGC autophagy.

In bovine ovaries, follicles are recruited and grow to preovulatory follicles following gonadotropin stimulation. However, most recruited follicles undergo atresia and only one follicle progresses to ovulation in each oestrous cycle (Adhikari \& Liu 2009, Yang et al. 2016). Most of the studies on follicular atresia in cattle focus on GC apoptosis; however, our studies reveal that autophagy occurs in bovine granulosa cells, as has been shown previously in rodents (Choi et al. 2010, HulasStasiak \& Gawron 2011, Shen et al. 2017). Autophagy is regulated in part by miRNAs. Zhou et al. (2016) demonstrated that miR-let-7g promotes autophagy in mouse GCs through the downregulation of IGF1R. Yang et al. (2017) described a mechanism by which miR-141 inhibited Hepatitis B virus (HBV) replication by targeting Sirt1 and inhibiting autophagy. In the mouse ovary, miR21 is transcriptionally upregulated in vivo in response to $\mathrm{LH}$, and both in vivo and in vitro, miR-21 knockdown caused an increase in GCs apoptosis (Carletti et al. 2010). In pigs, miR-21 was differentially expressed in the oocyte during meiotic maturation and miR-21 expression in MII-arrested oocytes matured in vitro was not affected by gonadotropins or the presence of cumulus cells (Wright et al. 2016). The MiR-21 gene is transcribed by RNA polymerase II into a pri-miR-21 which is further processed by RNase III complex to generate miR-21-5p (guide strand) and miR-21-3p (passenger strand) (Jiao et al. 2017). Most studies of miR-21-3p have focused on tumor cells through patterns associated with apoptosis (Pink et al. 2015, Lo et al. 2017, Hou et al. 2018). However, miR-21 downregulates autophagy through a PTEN/AKT/HIF-1 $\alpha$ feedback loop in cancer cells, which correlates with angiogenesis and contributes to tumor development (Ali et al. 2010, Liu et al. 2011). In this study, miR-21-3p mimics or inhibitor were transfected into BGCs, and the mimic decreased autophagy while the inhibitor increased autophagy in BGCs. MDC staining confirmed the presence of autophagosomes in BGCs after transfection of miR-21-3p inhibitor.

Our results demonstrated that VEGFA contributes to autophagy and is a novel target of miR-21-3p in BGCs. 


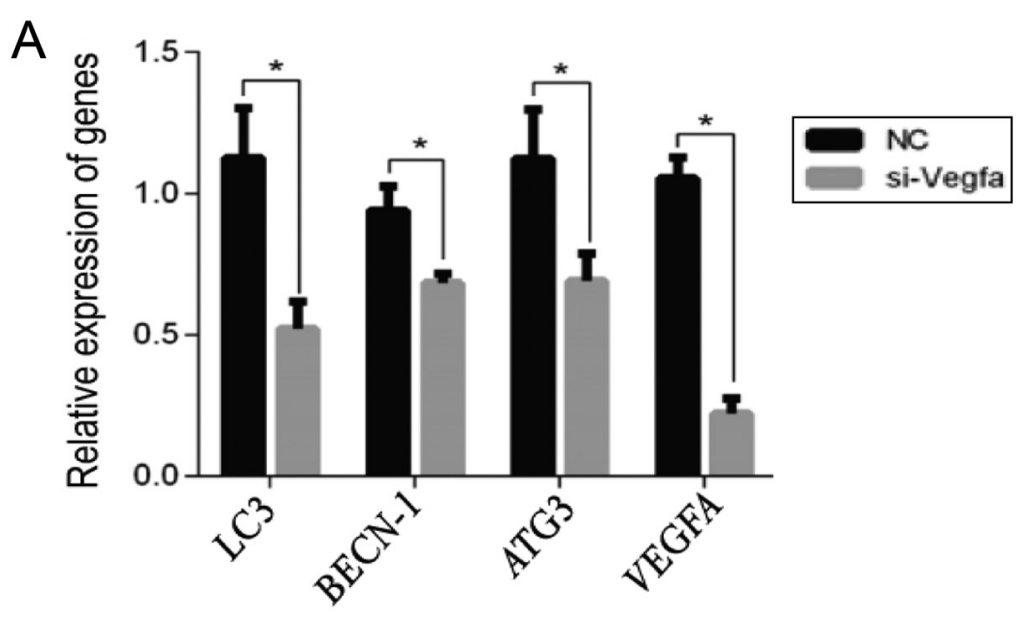

B
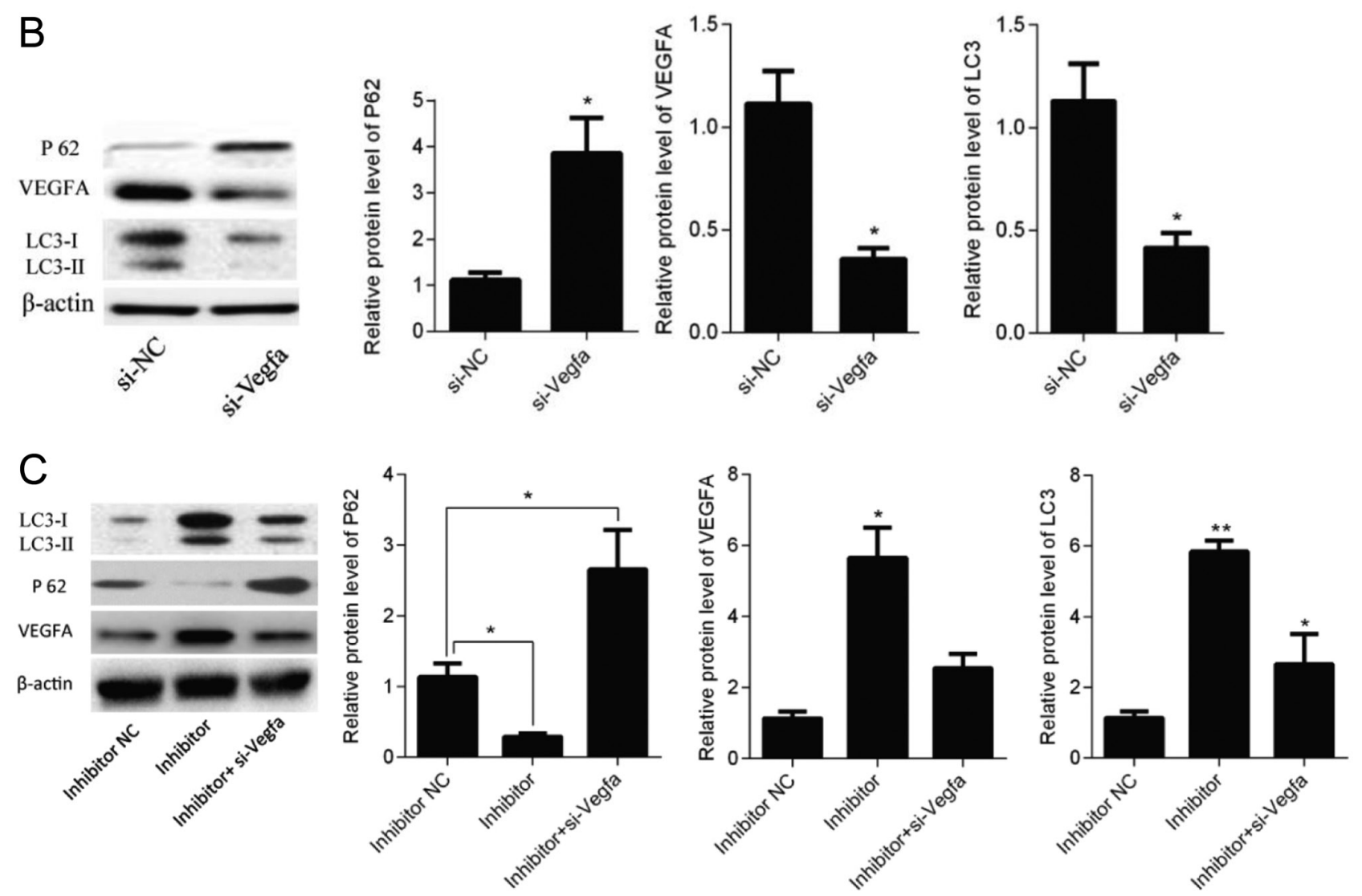

Figure 4 Knockdown of VEGFA inhibits autophagy in BGCs. (A) Real-time PCR analysis for LC3, BECN-1, ATG3 and VEGFA mRNA after transfection with si-Vegfa for $6 \mathrm{~h}$ and cultured for $42 \mathrm{~h}$ with fresh medium. (B) Western blot analysis of LC3, VEGFA and P62 expression after transfection with si-Vegfa for $6 \mathrm{~h}$ and cultured for $42 \mathrm{~h}$ with fresh medium. (C) Western blot analysis of LC3, VEGFA and P62 after co-transfection with miR-21-3p inhibitors and si-VEGFA for $6 \mathrm{~h}$ and cultured for $42 \mathrm{~h}$ with fresh medium. Data are means \pm S.E.M. of three independent replicate, bars with no common asterisk are significantly different $(P<0.05)$.

VEGFA plays a crucial role during angiogenesis and is associated with increased vascularity in ovarian follicles of cattle. In the ovary, VEGFA mRNA abundance was greater in GC than TC, and VEGFA expression decreased in TC during follicle development (Nichols et al. 2019). It was well documented that both $\mathrm{LH}$ and $\mathrm{FSH}$ regulate Vegfa expression in mice GCs and signal via the transcription factor hypoxia inducible factor 1 (HIF1), and which acts through a single hypoxia response element in the Vegfa promoter to exert its regulatory functions (Rico et al. 2014). Melatonin is effective against follicular atresia and preserves antral follicles by decreasing VEGFA expression in rat ovary (Kandemir et al. 2018). Although studies demonstrated that VEGFA 

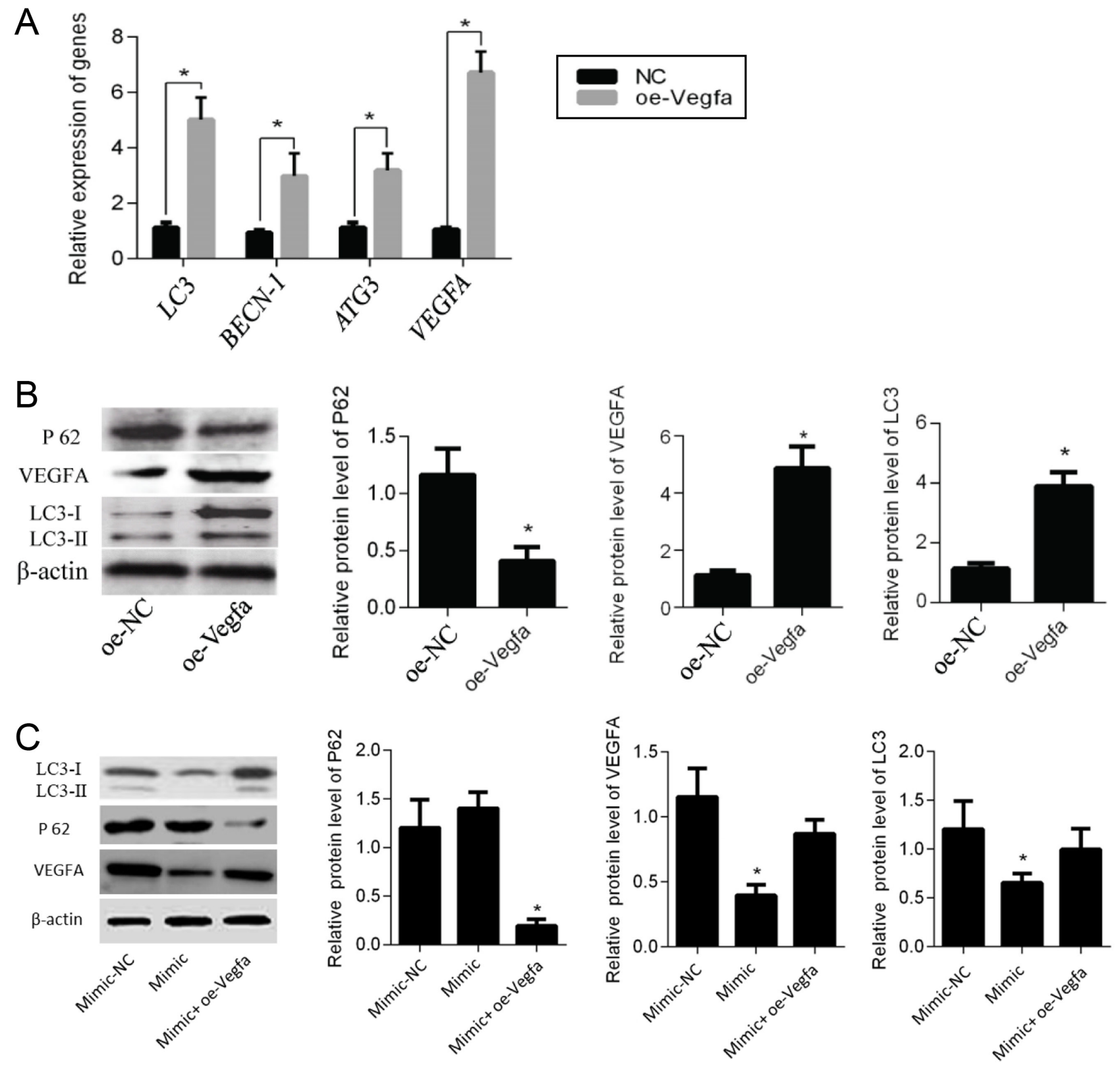

Figure 5 Overexpression of VEGFA promotes autophagy in BGCs. (A) Real-time PCR analysis of $L C 3, B E C N-1$, ATG3 and VEGFA after transfection with oe-Vegfa for $6 \mathrm{~h}$ and cultured for $42 \mathrm{~h}$ with fresh medium. (B) Western blot analysis of LC3, VEGFA and P62 in the presence of oe-VEGFA treatment for $6 \mathrm{~h}$ and cultured for $42 \mathrm{~h}$ with fresh medium. (C) Western blot analysis of LC3, VEGFA and P62 after co-transfection of the miR-21-3p inhibitor and oe-Vegfa for $6 \mathrm{~h}$ and cultured for $42 \mathrm{~h}$ with fresh medium. Data are means \pm S.E.M. of three independent replicate, bars with no common asterisk are significantly different $(P<0.05)$.

significantly increases the expression of autophagyrelated genes including BECN-1, ATG4, ATG5, and LC3-II, indicating that VEGF induces endothelial cells tubular formation via autophagy induction (Hicklin \& Ellis 2005), the role of VEGFA on the regulation of follicular cells autophagy is unknown. In this study, the activity of luciferase reporter genes that are upstream of the VEGFA-3'UTR was analyzed in the presence of miR-21-3p and VEGFA was identified as a target of miR-21-3p during autophagy in BGCs.
We further showed that miR-21-3p inhibits BGCs autophagy by targeting $\mathrm{p}-\mathrm{AKT}$. Increasing evidence suggests that phosphatidylinositol-3-kinase/protein kinase B (PI3K-AKT) signaling regulates ovarian function, including the recruitment of primordial follicles, GCs proliferation, survival of the corpus luteum and oocyte maturation (Reddy et al. 2008, Adhikari \& Liu 2009, Makker et al. 2014). In addition, miRNA regulates PI3K-AKT signaling, which adds complexity to the system (Xu \& Mo 2012). Specifically, miRNAs such as 
A

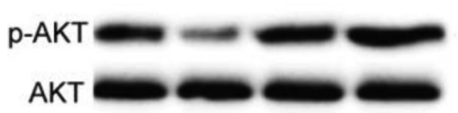

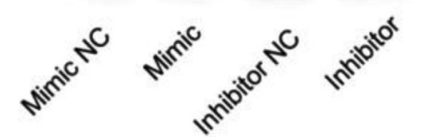

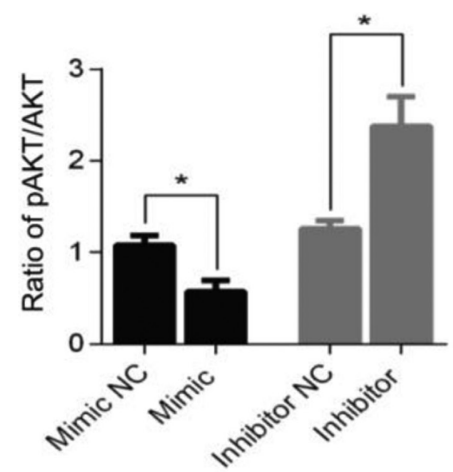

B
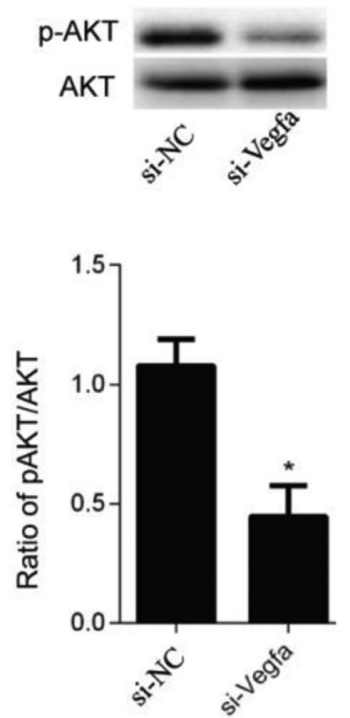

C
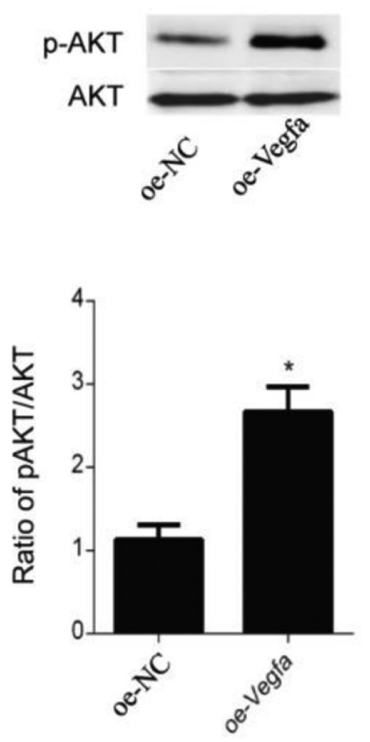

D

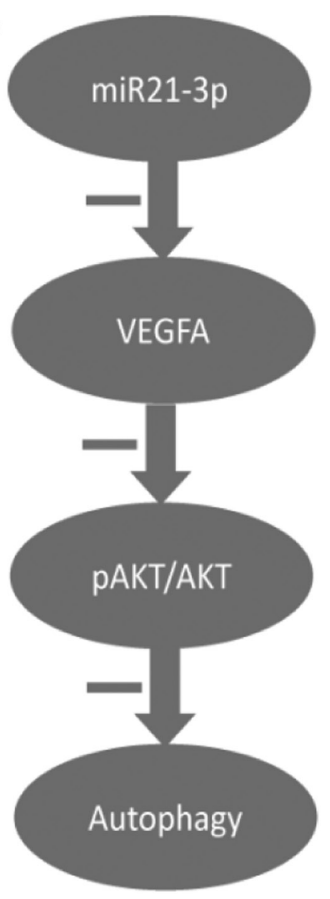

Figure 6 miR-21-3p downregulates AKT phosphorylation in BGCs. Western blot analysis of AKT and p-AKT in BGCs following transfected with (A) miR-21-3p mimics or inhibitor; (B) si-Vegfa; and (C) oe-Vegfa plasmids for $6 \mathrm{~h}$ and cultured for $42 \mathrm{~h}$ with fresh medium. (D) A model of how miR-21-3p regulates autophagy in BGCs. miR-21-3p directly targets VEGFA, resulting in the downregulation of p-AKT/AKT signaling, promoting BGC autophagy. ' - ' means the inhibition function. Data are means \pm S.E.M. of three independent replicate, bars with no common asterisk are significantly different $(P<0.05)$.

miR-494 and miR-20a regulate PTEN expression and downstream genes of the PI3K-Akt pathway (Luo et al. 2013, Andreas et al. 2016). In the rat ovary, VEGFA has a role as an antiapoptotic and proliferative factor to regulate follicular growth and development through PI3K/AKT signaling pathway (Abramovich et al. 2010). In this study, the suppression of VEGFA was responsible for the reduced effects of autophagy on miR-21-3p in BGCs. In addition, AKT phosphorylation decreased in the presence of miR-21-3p mimics and increased in the presence of the miR-21-3p inhibitor. Importantly, VEGFA overexpression increased p-AKT levels in BGCs.

\section{Conclusions}

In conclusion, we demonstrate autophagy for the first time in BGCs and show that miR-21-3p contributes to GCs autophagy by directly targeting VEGFA and attenuating PI3K/AKT signaling. These findings advance our understanding of mechanisms of follicular growth and demise and facilitate the development of novel strategies to reduce the number of follicles that undergo degeneration in bovine ovaries.

\section{Declaration of interest}

The authors declare that there is no conflict of interest that could be perceived as prejudicing the impartiality of the research reported.

Reproduction (2019) 158 441-452

\section{Funding}

This research was supported by the National Natural Science Foundation of China (Grant No. 31572406), the National Key Research and Development Program (Grant No.2016YFD0500500), the Key Laboratories Special Project of Qinghai (Grant No.2013-Z-Y03).

\section{Author contribution statement}

LM and YZ performed the experiment and collected the data. ZJ conceived, conducted and supervised the study and had substantial inputs into the analysis. XT and ZJ drafted the manuscript. HG, NL and YG contributed to interpreting data and writing. LH and SL made the suggestion for data collection and analysis, revised the drafts.

\section{Acknowledgements}

The authors thank Dingxin Jia and Nina Zhang for assistance in the laboratory. They thank Shujie Liu for preliminary work on this project.

\section{References}

Abramovich D, Irusta G, Parborell F \& Tesone M 2010 Intrabursal injection of vascular endothelial growth factor trap in eCG-treated prepubertal rats inhibits proliferation and increases apoptosis of follicular cells involving the PI3K/AKT signaling pathway. Fertility and Sterility 93 1369-1377. (https://doi.org/10.1016/j.fertnstert.2009.01.127)

https://rep.bioscientifica.com 
Adhikari D \& Liu K 2009 Molecular mechanisms underlying the activation of mammalian primordial follicles. Endocrine Reviews 30 438-464. (https://doi.org/10.1210/er.2008-0048)

Ali S, Ahmad A, Banerjee S, Padhye S, Dominiak K, Schaffert JM, Wang Z, Philip PA \&, Sarkar FH 2010 Gemcitabine sensitivity can be induced in pancreatic cancer cells through modulation of miR-200 and miR-21 expression by curcumin or its analogue CDF. Cancer Research 703606 3617. (https://doi.org/10.1158/0008-5472.CAN-09-4598)

Andreas E, Hoelker M, Neuhoff C, Tholen E, Schellander K, Tesfaye D \& Salilew-Wondim D 2016 MicroRNA 17-92 cluster regulates proliferation and differentiation of bovine granulosa cells by targeting PTEN and BMPR2 genes. Cell and Tissue Research 366 219-230. (https://doi. org/10.1007/s00441-016-2425-7)

Cao B, Camden AJ, Parnell LA \& Mysorekar IU 2017 Autophagy regulation of physiological and pathological processes in the female reproductive tract. American Journal of Reproductive Immunology 77 e12650. (https:// doi.org/10.1111/aji.12650)

Carletti MZ, Fiedler SD \& Christenson LK 2010 MicroRNA 21 blocks apoptosis in mouse periovulatory granulosa cells. Biology of Reproduction 83 286-295. (https://doi.org/10.1095/biolreprod.109.081448)

Chai ZT, Kong J, Zhu XD, Zhang YY, Lu L, Zhou JM, Wang LR, Zhang KZ, Zhang QB, Ao JY, et al. 2013 MicroRNA-26a inhibits angiogenesis by down-regulating VEGFA through the PIK3C2alpha/Akt/HIF-1alpha pathway in hepatocellular carcinoma. PLOS ONE 8 e77957. (https://doi. org/10.1371/journal.pone.0077957)

Choi J, Jo M, Lee E \& Choi D 2011 Induction of apoptotic cell death via accumulation of autophagosomes in rat granulosa cells. Fertility and Sterility 95 1482-1486. (https://doi.org/10.1016/j.fertnstert.2010.06.006)

Choi J, Jo M, Lee E \& Choi D 2014 AKT is involved in granulosa cell autophagy regulation via mTOR signaling during rat follicular development and atresia. Reproduction 147 73-80. (https://doi. org/10.1530/REP-13-0386)

Choi JY, Jo MW, Lee EY, Yoon BK \& Choi DS 2010 The role of autophagy in follicular development and atresia in rat granulosa cells. Fertility and Sterility 93 2532-2537. (https://doi.org/10.1016/j.fertnstert.2009.11.021)

de la Torre FJ, Garcia A, Gil-Moreno A, Planaguma J, Reventos J, Ramon y Cajal S \& Xercavins J 2007 Apoptosis in epithelial ovarian tumours prognostic significance of clinical and histopathologic factors and its association with the immunohistochemical expression of apoptotic regulatory proteins (p53, bcl-2 and bax). European Journal of Obstetrics, Gynecology, and Reproductive Biology 130 121-128. (https://doi. org/10.1016/j.ejogrb.2005.11.048)

D'Herde K, De Prest B \& Roels F 1996 Subtypes of active cell death in the granulosa of ovarian atretic follicles in the quail (Coturnix coturnix japonica). Reproduction, Nutrition, Development 36 175-189. (https:// doi.org/10.1051/rnd:19960203)

Edinger AL \& Thompson CB 2002 Akt maintains cell size and survival by increasing mTOR-dependent nutrient uptake. Molecular Biology of the Cell 13 2276-2288. (https://doi.org/10.1091/mbc.01-12-0584)

Faddy MJ, Gosden RG, Gougeon A, Richardson SJ \& Nelson JF 1992 Accelerated disappearance of ovarian follicles in mid-life: implications for forecasting menopause. Human Reproduction 7 1342-1346.(https:// doi.org/10.1093/oxfordjournals.humrep.a137570)

Gawriluk TR, Hale AN, Flaws JA, Dillon CP, Green DR \& Rucker EB 2011 Autophagy is a cell survival program for female germ cells in the murine ovary. Reproduction 141 759-765. (https://doi.org/10.1530/REP-100489)

Gawriluk TR \& Rucker EB 2015 BECN1, corpus luteum function, and preterm labor. Autophagy 11 183-184. (https://doi.org/10.4161/15548 627.2014.984269)

Hahn-Windgassen A, Nogueira V, Chen CC, Skeen JE, Sonenberg N \& Hay N 2005 Akt activates the mammalian target of rapamycin by regulating cellular ATP level and AMPK activity. Journal of Biological Chemistry 280 32081-32089. (https://doi.org/10.1074/jbc.M502876200)

Hicklin DJ \& Ellis LM 2005 Role of the vascular endothelial growth factor pathway in tumor growth and angiogenesis. Journal of Clinical Oncology 23 1011-1027. (https://doi.org/10.1200/JCO.2005.06.081)

Hou N, Guo Z, Zhao G, Jia G, Luo B, Shen X \& Bai Y 2018 Inhibition of microRNA-21-3p suppresses proliferation as well as invasion and induces apoptosis by targeting RNA-binding protein with multiple splicing through Smad4/extra cellular signal-regulated protein kinase signalling pathway in human colorectal cancer HCT116 cells. Clinical
\& Experimental Pharmacology \& Physiology 45 729-741. (https://doi. org/10.1111/1440-1681.12931)

Hulas-Stasiak M \& Gawron A 2011 Follicular atresia in the prepubertal spiny mouse (Acomys cahirinus) ovary. Apoptosis 16 967-975. (https:// doi.org/10.1007/s10495-011-0626-9)

Jiang Z, Guerreronetro HM, Juengel JL \& Price CA 2013 Divergence of intracellular signaling pathways and early response genes of two closely related fibroblast growth factors, FGF8 and FGF18, in bovine ovarian granulosa cells. Molecular and Cellular Endocrinology 375 97-105. (https://doi.org/10.1016/j.mce.2013.05.017)

Jiao W, Leng X, Zhou Q, Wu Y, Sun L, Tan Y, Ni H, Dong X, Shen T, Liu Y, et al. 2017 Different miR-21-3p isoforms and their different features in colorectal cancer. International Journal of Cancer 141 2103-2111. (https://doi.org/10.1002/ijc.30902)

Kandemir YB, Konuk E, Behram M \& Sindel M 2018 Effect of melatonin on the expression of VEGF-A and on the degeneration of follicle reserve in rat ovary. EurAsian Journal of Medicine 50 160-163. (https://doi. org/10.5152/eurasianjmed.2018.17361)

Krysko DV, Diez-Fraile A, Criel G, Svistunov AA, Vandenabeele P \& D'Herde K 2008 Life and death of female gametes during oogenesis and folliculogenesis. Apoptosis 13 1065-1087. (https://doi.org/10.1007/ s10495-008-0238-1)

Liu LZ, Li C, Chen Q, Jing Y, Carpenter R, Jiang Y, Kung HF, Lai L \& Jiang BH 2011 MiR-21 induced angiogenesis through AKT and ERK activation and HIF-1 $\alpha$ expression. PLOS ONE 6 e19139. (https://doi. org/10.1371/journal.pone.0019139)

Lo SN, Wang CW, Chen YS, Huang CC, Wu TS, Li LA, Lee IJ \& Ueng YF 2017 Berberine activates aryl hydrocarbon receptor but suppresses CYP1A1 induction through miR-21-3p stimulation in MCF-7 breast cancer cells. Molecules 22 22111847. (https://doi.org/10.3390/molecules22111847)

Luo X, Don Z, Chen Y, Yang L \& Lai D 2013 Enrichment of ovarian cancer stem-like cells is associated with epithelial to mesenchymal transition through an miRNA-activated AKT pathway. Cell Proliferation 46 436446. (https://doi.org/10.1111/cpr.12038)

Makker A, Goel MM \& Mahdi AA 2014 PI3K/PTEN/Akt and TSC/mTOR signaling pathways, ovarian dysfunction, and infertility: an update. Journal of Molecular Endocrinology 53 R103-R118. (https://doi. org/10.1530/JME-14-0220)

Matsuda F, Inoue N, Manabe N \& Ohkura S 2012 Follicular growth and atresia in mammalian ovaries: regulation by survival and death of granulosa cells. Journal of Reproduction and Development 58 44-50. (https://doi.org/10.1262/jrd.2011-012)

Megraw M, Sethupathy P, Corda B \& Hatzigeorgiou AG 2007 miRGen: a database for the study of animal microRNA genomic organization and function. Nucleic Acids Research 35 D149-D155. (https://doi. org/10.1093/nar/gkl904)

Nichols JA, Perego MC, Schütz LF, Hemple AM \& Spicer LJ 2019 Hormonal regulation of vascular endothelial growth factor A (VEGFA) gene expression in granulosa and theca cells of cattle1. Journal of Animal Science 97 3034-3045. (https://doi.org/10.1093/jas/skz164)

Perla MB, Ileabett MEV, Fatma V, Joel ER, Adriana R, Josean F, María JM \& Pablo EV 2016 Targeting miR-21-3p inhibits proliferation and invasion of ovarian cancer cells. Oncotarget 24 36321-36335.

Petrocca F, Visone R, Onelli MR, Shah MH, Nicoloso MS, de Martino I, Iliopoulos D, Pilozzi E, Liu CG, Negrini M, et al. 20082008 E2F1regulated microRNAs impair TGF $\beta$-dependent cell-cycle arrest and apoptosis in gastric cancer. Cancer Cell 13 272-286. (https://doi. org/10.1016/j.ccr.2008.02.013)

Pink RC, Samuel P, Massa D, Caley DP, Brooks SA \& Carter DRF 2015 The passenger strand, miR-21-3p, plays a role in mediating cisplatin resistance in ovarian cancer cells. Gynecologic Oncology 137 143-151. (https://doi.org/10.1016/j.ygyno.2014.12.042)

Reddy P, Liu L, Adhikari D, Jagarlamudi K, Rajareddy S, Shen Y, Du C, Tang W, Hamalainen T, Peng SL, et al. 2008 Oocyte-specific deletion of Pten causes premature activation of the primordial follicle pool. Science 319 611-613. (https://doi.org/10.1126/science.1152257)

Rico C, Dodelet-Devillers A, Paquet M, Tsoi M, Lapointe E, Carmeliet P \& Boerboom D 2014 HIF1 activity in granulosa cells is required for FSH-regulated Vegfa expression and follicle survival in mice. Biology of Reproduction 90 135. (https://doi.org/10.1095/biolreprod.113.115634)

Shen M, Jiang Y, Guan Z, Cao Y, Li L, Liu H \& Sun SC 2017 Protective mechanism of $\mathrm{FSH}$ against oxidative damage in mouse ovarian granulosa 
cells by repressing autophagy. Autophagy 13 1364-1385. (https://doi.or g/10.1080/15548627.2017.1327941)

Shibuya M 2011 Vascular endothelial growth factor (VEGF) and its receptor (VEGFR) signaling in angiogenesis: A crucial target for anti- and proangiogenic therapies. Genes and Cancer 2 1097-1105. (https://doi. org/10.1177/1947601911423031)

Song ZH, Yu HY, Wang P, Mao GK, Liu WX, Li MN, Wang HN, Shang YL, Liu C, Xu ZL, et al. 2015 Germ cell-specific Atg7 knockout results in primary ovarian insufficiency in female mice. Cell Death and Disease 6 e1589. (https://doi.org/10.1038/cddis.2014.559)

Volinia S, Calin GA, Liu CG, Ambs S, Cimmino A, Petrocca F, Visone R, Iorio M, Roldo C, Ferracin M, et al. 2006 A microRNA expression signature of human solid tumors defines cancer gene targets. Proceedings of the National Academy of Sciences of the United States of America 103 2257-2261. (https://doi.org/10.1073/pnas.0510565103)

Wright EC, Hale BJ, Yang CX, Njoka JG \& Ross JW 2016 MicroRNA-21 and PDCD4 expression during in vitro oocyte maturation in pigs. Reproductive Biology and Endocrinology: RB\&E 14 21. (https://doi. org/10.1186/s12958-016-0152-2)

Xu M \& Mo YY 2012 The Akt-associated microRNAs. Cellular and Molecular Life Sciences 69 3601-3612. (https://doi.org/10.1007/ s00018-012-1129-8)

Xu X, Wang H, Liu S, Xing C, Liu Y, Aodengqimuge, Zhou W, Yuan X, Ma Y, Hu M, et al. 2016 TP53-dependent autophagy links the ATR-CHEK1 axis activation to proinflammatory VEGFA production in human bronchial epithelial cells exposed to fine particulate matter (PM2.5). Autophagy 12 1832-1848. (https://doi.org/10.1080/15548627.2016.1204496)

Yang Y, Cheung HH, Law WN, Zhang C, Chan WY, Pei X \& Wang Y 2016 New insights into the role of autophagy in ovarian cryopreservation by vitrification. Biology of Reproduction 94 137. (https://doi.org/10.1095/ biolreprod.115.136374)

Yang Y, Liu Y, Xue J, Yang Z, Shi Y, Shi Y, Lou G, Wu S, Qi J, Liu W, et al. 2017 MicroRNA-141 targets Sirt1 and inhibits autophagy to reduce HBV replication. Cellular Physiology and Biochemistry 41 310-322. (https:// doi.org/10.1159/000456162)
Yu L, Chen Y \& Tooze SA 2018 Autophagy pathway: cellular and molecular mechanisms. Autophagy 14 207-215. (https://doi.org/10.1080/1554862 7.2017.1378838)

Yu YS, Sui HS, Han ZB, Li W, Luo MJ \& Tan JH 2004 Apoptosis in granulosa cells during follicular atresia: relationship with steroids and insulin-like growth factors. Cell Research 14 341-346. (https://doi.org/10.1038/ sj.cr.7290234)

Zhang L, Volinia S, Bonome T, Calin GA, Greshock J, Yang N, Liu CG, Giannakakis A, Alexiou P, Hasegawa K, et al. 2008 Genomic and epigenetic alterations deregulate microRNA expression in human epithelial ovarian cancer. Proceedings of the National Academy of Sciences of the United States of America 105 7004-7009. (https://doi. org/10.1073/pnas.0801615105)

Zhou J, Peng X \& Mei S 2019 Autophagy in ovarian follicular development and atresia. International Journal of Biological Sciences 15 726-737. (https://doi.org/10.7150/ijbs.30369)

Zhou J, Yao W, Li C, Wu W, Li Q \& Liu H 2017 Administration of folliclestimulating hormone induces autophagy via upregulation of HIF-1 $\alpha$ in mouse granulosa cells. Cell Death and Disease 8 e3001. (https://doi. org/10.1038/cddis.2017.371)

Zhou J, Yao W, Liu K, Wen Q, Wu W, Liu H \& Li Q 2016 MicroRNA let-7g regulates mouse granulosa cell autophagy by targeting insulin-like growth factor 1 receptor. The International Journal of Biochemistry and Cell Biology 78 130-140. (https://doi.org/10.1016/j. biocel.2016.07.008)

Received 2 July 2019

First decision 24 July 2019

Revised manuscript received 16 September 2019

Accepted 23 September 2019 